\title{
Clinical longevity of extensive direct composite restorations in amalgam replacement: Up to 3.5 years follow-up
}

\author{
Scholtanus, Johannes D ; Özcan, Mutlu
}

\begin{abstract}
OBJECTIVES: This prospective clinical trial evaluated the longevity of direct resin composite (DRC) restorations made on stained dentin that is exposed upon removal of existing amalgam restorations in extensive cavities with severely reduced macro-mechanical retention for amalgam replacement. METHODS: Between January 2007 and September 2013, a total of 88 patients (57 women, 31 men; mean age: 51.6 years old) received extensive cusp replacing DRCs $(n=118)$ in the posterior teeth. DRCs were indicated for replacement of existing amalgam restorations where dentin substrates were stained by amalgam. After employing a three-step total-etch adhesive technique (Quadrant Unibond Primer, Quadrant Unibond Sealer, Cavex), cavities were restored using a hybrid composite (Clearfil Photo Posterior, Kuraray). At baseline and thereafter every 6 months, restorations were checked upon macroscopically visible loss of anatomical contour, marginal discolouration, secondary caries, fractures, debonding and endodontic problems. Restorations were scored as failed if any operative intervention was indicated for repair, partial or total replacement. RESULTS: Restorations were observed for a minimum of seven, and maximum 96 months (mean: 40.3 months). In total, four failures were observed due to fracture $(n=1)$, endodontic complications $(n=2)$ and inadequate proximal contact $(n=1)$. Failures were related neither to inadequate adhesion nor to secondary caries. Cumulative survival rate was $96.6 \%$ (95\% CI: $89-95)$ up to a mean observation time of 40.3 months (Kaplan-Meier) with an annual failure rate of $0.9 \%$. CONCLUSION: In case of amalgam replacement, dentin that is exposed upon removal of existing amalgam restorations does not impair clinical longevity of extended cusp replacing direct resin composite restorations. CLINICAL SIGNIFICANCE: Extensive amalgam restorations can be replaced with a variety of treatment options. This clinical study indicates that in such cases directly applied resin based composites offer a reliable and low-cost treatment option, even if dentin is stained by amalgam corrosion products.
\end{abstract}

DOI: https://doi.org/10.1016/j.jdent.2014.06.008

Posted at the Zurich Open Repository and Archive, University of Zurich ZORA URL: https://doi.org/10.5167/uzh-100658

Journal Article

Accepted Version

Originally published at:

Scholtanus, Johannes D; Özcan, Mutlu (2014). Clinical longevity of extensive direct composite restorations in amalgam replacement: Up to 3.5 years follow-up. Journal of Dentistry, 42(11):1404-1410.

DOI: https://doi.org/10.1016/j.jdent.2014.06.008 


\section{Clinical longevity of extensive direct composite restorations in amalgam replacement: \\ Up to 3.5 years follow-up}

\section{Johannes D. Scholtanus ${ }^{a}$, Mutlu Özcan ${ }^{b}$}

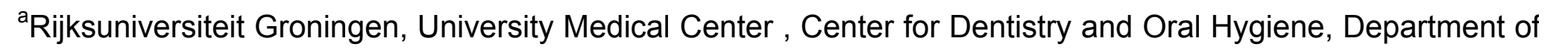
Fixed and Removable Prosthodontics, Groningen, The Netherlands.

bUniversity of Zurich, Dental Materials Unit, Center for Dental and Oral Medicine, Clinic for Fixed and Removable Prosthodontics and Dental Materials Science, Zurich, Switzerland.

Short title: Longevity of extensive direct composite restorations in amalgam replacement

${ }^{*}$ Part of this study has been presented at the 46th International Association for Dental Research Continental European Division (IADR/CED), September, 4-7th, 2013, Florence, Italy.

*Corresponding author: Johannes D. Scholtanus, Department of Periodontology, Conservative Dentistry and Oral Hygiene, Groningen, Center for Dentistry and Oral Hygiene, University Medical Center Groningen, The University of Groningen, Antonius Deusinglaan 1, 9713 AV, Groningen, The Netherlands. Tel: +31 6 51537681; Fax: +31 503632696 ; E-mail: hans.scholtanus@gmail.com 


\section{ABSTRACT}

Objectives: This prospective clinical trial evaluated the longevity of direct resin composite (DRC) restorations made on stained dentin that is exposed upon removal of existing amalgam restorations in extensive cavities with severely reduced macro-mechanical retention for amalgam replacement.

Methods: Between January 2007 and September 2013, a total of 88 patients (57 women, 31 men; mean age: 51.6 years old) received extensive cusp replacing DRCs $(\mathrm{N}=118)$ in the posterior teeth. DRCs were indicated for replacement of existing amalgam restorations where dentin substrates were stained by amalgam. After employing 3-step total-etch adhesive technique (Quadrant Unibond Primer, Quadrant Unibond Sealer, Cavex), cavities were restored using a hybrid composite (Clearfil Photo Posterior, Kuraray). At baseline and thereafter every 6 months, restorations were checked upon macroscopically visible loss of anatomical contour, marginal discoloration, secondary caries, fractures, debonding and endodontic problems. Restorations were scored as failed if any operative intervention was indicated for repair, partial or total replacement.

Results: Restorations were observed for a minimum of 7, and maximum 96 months (mean: 40.3 months). In total, 4 failures were observed due to fracture $(n=1)$, endodontic complications $(n=2)$ and inadequate proximal contact $(n=1)$. Failures were neither related to inadequate adhesion, nor to secondary caries. Cumulative survival rate was $96.6 \%$ (95\% Cl: $89-95)$ up to a mean observation time of 40.3 months (KaplanMeier) with an annual failure rate of $0.9 \%$.

Conclusion: In case of amalgam replacement, dentin that is exposed upon removal of existing amalgam restorations does not impair clinical longevity of extended cusp replacing direct resin composite restorations.

Keywords: Adhesive dentistry, Amalgam, Clinical study, Cusp replacement, Direct composite restorations, Minimal invasive dentistry 


\section{Introduction}

Amalgam has proven to be a predictable material over the years for restorations of posterior teeth, even in extensive restorations. Numerous decayed posterior teeth have been saved or had their lifetime extended by amalgam restorations. ${ }^{1}$

Almost three decades ago, resin composite (hereon: composite) materials have been regarded as not suitable for restoration of posterior teeth, especially in cases of extensive loss of tooth substance. Main points of concern were wear, marginal integrity, adhesion to dentin, radiopacity, dimensional stability and compressive strength. ${ }^{2}$ However, with the advances in filler and polymer technologies and adhesive resins for enamel and dentin, composites progressed and became predictable materials even for use in stress bearing situations. Today, they are often regarded as the preferred material of choice not only for small restorations ${ }^{3,4}$ but also for large and stress bearing direct posterior restorations. ${ }^{5}$ This implicates that if old amalgams need to be replaced, in many cases they will be replaced by composite restorations even in extensive cavity designs.

After removal of amalgam, dentin is commonly characterized by dark staining underneath the amalgam. This stain is not limited to the interface but protrudes into dentin in pulpal direction. Corrosion products from amalgam are held responsible for this kind of dentin staining. ${ }^{6}$ It has been demonstrated that especially $\mathrm{Sn}$ and $\mathrm{Zn}$ ions from amalgam can penetrate dentin, underlying amalgam. ${ }^{6}$ Until now it is not clear what is the impact of staining in respect to adhesive properties in clinical circumstances. In an in vitro study, Harnirattisai et al. ${ }^{7}$ reported decreased bond strengths of composites to amalgam stained dentin.

The objective of this study was to evaluate the clinical longevity of extensive cusp-replacing direct composite restorations (DCR) made after amalgam replacement on stained dentin substrate with amalgam ions, in extensive cavities with severely reduced macro-mechanical retention. The hypothesis tested was 
that dentin that is exposed upon removal of existing amalgam restorations is not a reliable substrate for direct restorations.

\section{Materials and methods}

2.1 Study design

The brands, types, chemical compositions and manufacturers of the materials used in this study are listed in Table 1.

2.2 Inclusion and exclusion criteria

Between January 2007 and September 2013, a total of 118 extensive cusp replacing DRCs were placed in 88 patients ( 57 women, 31 men; mean age: 51.6 years old) in the posterior teeth in a general practice. As the restorations in this study were made as a part of standard dental care with the employed treatment philosophy based on minimal invasive dentistry, no ethical committee approval was requested.

DRCs were indicated for replacement of existing amalgam restorations where dentin substrates were stained by amalgam ions. Information was given to each patient regarding the alternative treatment options. Based on the informed consent, patients wished to have DCRs because of lower costs and the less invasiveness of the treatment compared to indirect restorations. Extensive restorations were scheduled because of complete or incomplete fracture of tooth structure, weakened cusps after cavity preparation, and/or secondary caries. An exact calculation of the amount of enamel and dentin surfaces present in a cavity in relation to the overall cavity margins was not feasible. Therefore, the zone of unstained dentin along the cavity outline, the absence of at least one cusp in premolars, and at least two cusps in molars were considered during inclusion and for classification. The inclusion and exclusion criteria for the teeth in this study are listed in Table 2. 


\subsection{Clinical procedures and restoration fabrication}

Cavity preparation and restoration was performed in the general dental practice setting employing fourhanded dentistry. One operator applied all the restorations who has experience in adhesive dentistry (>25 years since graduation).

Existing amalgam was removed with diamond burs (Rondomant 233/010, Heraeus Kulzer, Hanau Germany) using high-speed hand piece under water coolant. Corrosion material at the amalgam dentin interface and softened dentin was removed with round tungsten carbide burs (Komet H1S 012, 014 and 018 , Brasseler, Lemgo, Germany) until dentin felt hard with a blunt explorer, and dentin was not stained until approximately $1 \mathrm{~mm}$ from cavity margins. Central stained but hard dentin was left in place. Weakened cusps were cut for coverage with a layer of composite of at least $1.5 \mathrm{~mm}$. Enamel cavity margins were bevelled with fine diamond burs (Komet 8852.012, Brasseler).

Contoured sectional matrices (Contact Matrix, Danville Engineering, San Ramon, USA) or contoured circular matrix (Hawe contoured matrices nrs. 390 and 391, KerrHawe, Bioggio, Switzerland) in retainer were applied, with separating rings (Contact Rings, Danville Engineering) to obtain optimal proximal contacts. Dry field was created mainly with suction and cotton rolls. Rubberdam was not applied in all cases.

Cavities were conditioned using a 3-step total etch technique. Enamel margins and dentin was etched simultaneously with $37 \%$ phosphoric etching gel (Ultra-Etch, Ultradent, South Jordan, USA) for 20 seconds, rinsed with water spray for about 5 seconds. Then, primer (Quadrant Unibond Primer, Cavex Holland, Haarlem, The Netherlands) was applied for 20 seconds using microbrush, gently air-blown for 2 seconds and adhesive resin (Quadrant Unibond Sealer, Cavex Holland, Haarlem, The Netherlands) was applied, airthinned and photo-polymerized for 20 seconds using an LED device (Demi, Kerr, Middleton, USA) at $\sim 1000$ $\mathrm{mW} / \mathrm{cm}^{2}$. A midifil hybrid composite (Clearfil Photo Posterior, Kuraray, Tokyo, Japan) was applied in layers 
of maximum $2 \mathrm{~mm}$ with a syringe technique. Each layer of composite was polymerized using an LED polymerization device (Figs. 1a-b).

Restorations were finished with fine diamond burs, tungsten carbide burs and rubber points. Application protocol is summarized in Table 3. Also, the total treatment time was registered. Patients received individual instructions to maintain plaque control.

\subsection{Evaluation}

Patients attended the practice on a regular basis for periodic check-ups at 6 months intervals before and during the study. Restorations were scored as failed if any operative intervention was indicated for repair, partial or total replacement. The specific criteria for failure of restorations were defined in advance (Table 4). At baseline and thereafter every 6 months, restorations were checked upon technical (minute or gross fractures of tooth/restoration, debonding, food impaction due to contact loss) and for biological failures (caries, endodontic problems). Patients were asked to contact the practice if they would perceive any problem of the restored teeth.

2.5 Statistical analysis

Survival analyses were performed with statistical software program (SPSS 14.0; SPSS Inc, Chicago, IL, USA) using Kaplan-Meier and Log Rank (Mantel-Cox) tests to obtain the cumulative survival rates in relation to observation time. P values less than 0.05 were considered to be statistically significant in all tests.

\section{Results}

Restorations were observed for a minimum of 7, and maximum 96 months (mean: 40.3 months). No drop out was experienced with a recall rate of $100 \%$ after 96 months. Recalls were performed every 6 months after baseline measurements. Mean treatment time was approximately 45 minutes. Three DCRs were made under rubber dam. 
Distribution of restored teeth and restoration types in the maxilla and mandible is presented in Table 5. Altogether, 4 failures were observed due to fracture of the cusp $(n=1)$, endodontic complication $(n=2)$ and inadequate proximal contact $(n=1)$. The restoration with the cusp fracture had to be replaced. The two teeth with endodontic complications occurred after 14 months and 21 months because of endodontic fistula. They could be treated successfully and endodontic access opening were closed with composite. One patient complained of food impaction due to inadequate proximal contact tightness, which could be corrected by minor modification of the restoration.

All of the failures appeared in molars. Secondary caries was not observed in any of the restored teeth.

Cumulative survival rate was $96.6 \%(95 \% \mathrm{Cl}$ : $89-95)$ up to a mean observation time of 40.3 months (Kaplan-Meier) with an annual failure rate of $0.9 \%$ (Fig. 2). No significant difference was found between female and males ( $p>0.05)$ and premolars and molars ( $p>0.05)$.

\section{Discussion}

This study was designed to evaluate the retention of DRCs in cavities with dentin that is exposed upon removal of existing amalgam restorations. Since none of the experienced failures were related to adhesion to dentin, the hypothesis tested that dentin that is stained by amalgam ions is not a reliable substrate for direct restorations could be rejected.

Although clinical studies focusing on the survival of amalgam replacements with DCRs in cervical lesions (Class V) are available in the literature, ${ }^{8}$ in the general practice where this study was conducted the incidence of posterior amalgam replacements were more in common. Therefore, in this study the clinical performance of DCRs on amalgam stained dentin in need of extensive cusp replacement was evaluated for the posterior teeth. Cavities were excavated until dentin felt hard with a blunt explorer and stained dentin was removed only until $1 \mathrm{~mm}$ from the dentino-enamel junction, other stained dentin was left in place. By this route, we intended to create maximum amount of sound dentin along the outline of the cavities and 
leave abundant stained dentin in the center of the cavity. Cavity forms presented strongly reduced macromechanical retentive properties. Thus, retention of the DRCs was greatly dependent on adhesion to stained dentin.

Dentin in the evaluated teeth was supposed to be very heterogenic, namely the teeth have been previously exposed to carious attack, resulting in demineralization and sclerosis of dentinal tubules. Cavity preparation for amalgam restoration results in removal of infected dentin, leaving caries-affected dentin behind in the center of the cavity and some sound dentin along the margins of the cavity. This type of dentin becomes exposed to the restorative procedure with amalgam. Subsequently, during clinical function the tooth-restoration complex is subjected to chemical and physical processes in the oral environment leading to remineralization of dentin, deposition of corrosion products in marginal gaps and penetration of metal ions into dentin. It has been demonstrated that penetration of corrosion products is related to demineralized state of dentin. ${ }^{9-11}$ In case of amalgam removal, the clinician is often encountered with dentin that is compromised which makes it a questionable substrate for adequate bonding. Several studies found lower bond strengths in vitro for demineralized caries-affected dentin. ${ }^{12-16}$ To the authors' best knowledge, for stained demineralized dentin no data are available. Harnirattisai et al reported lower microtensile bond strengths of two adhesive resins to amalgam stained dentin, but the dentin in their study was harder than caries affected dentin. $^{7}$

Several authors have reported good or acceptable clinical behaviour of DRCs in posterior teeth for restorations in teeth that had not been previously restored with amalgam in an evaluation period of more than 10 years. ${ }^{13-15,17-19}$ Fracture of DRCs and secondary caries were the most frequent reasons for failure of such posterior composite restorations..$^{5,17,19,20}$ In this study, we found only one failure due to bulk fracture and none of the restorations failed because of secondary caries. For extensive cusp replacing DRCs survival data are limited. Laegreid et al. ${ }^{21}$ showed $87.7 \%$ survival in 3 years with an annual failure rate of 
4.2\%. On the other hand, Deliperi and Bardwell found no failures and excellent clinical behaviour of 25 DRCs in molars after 30 months. ${ }^{22}$ Previous studies did not report on the state of the dentin. In this clinical study, despite the compromised state and staining of the dentin, no debondings were experienced. The composite used in this study was a small particle hybrid material classified as midifil composite that shows superior physical properties terms of flexure strength, flexure modulus and fracture toughness. ${ }^{23}$ Under simulated occlusal loading, this composite demonstrated very low rate of marginal degradation. ${ }^{24}$ In a clinical study, the composite showed remarkable wear resistance after 3 years. ${ }^{25}$ Furthermore, it is one of the few materials that is still on the market since its introduction decades ago.

The adhesive approach chosen in this study was a 3-step total-etch procedure as this technique produces reliable adhesion in the laboratory studies and has proven to be very effective in clinical application. ${ }^{26,27}$ This adhesive system coupled with the use of a composite material with good physical properties, the quality of dentin as a substrate was compensated for being the weakest link. The number of failures $(n=2)$ because of endodontic problems (pulp necrosis) was low in regard to the extent of the restorations. Teeth in this study had a long history of previous caries, restoration and re-restoration. Thus, pulpal health might have been compromised already before the teeth were included in the study. After effective endodontic treatments and restoration of endodontic openings with composite, both teeth survived without any further complication. The single case of fracture was a bulk fracture that could not be associated with adhesive failure.

As no failure was directly associated with adhesive failure, it is concluded that under clinical conditions adhesion to dentin is not compromised when it is stained from amalgam ions. A possible explanation for these positive results may be that outward flow of dentinal fluid from obliterated dentinal tubules is condensed, reducing hydrophilic properties of dentin and facilitating hybrid layer formation. Since we used an adhesive resin without chemically active components, we do not assume that adhesion is improved by binding to metals in dentin. Several previous studies showed that demineralized dentin is susceptible to 
penetration of amalgam constituents, and especially $\mathrm{Sn}$ and $\mathrm{Zn}$ can penetrate into demineralized dentin. ${ }^{9-11}$ When these metals replace missing $\mathrm{Ca}$, as a kind of remineralization process, then etchability of dentin might be impaired, resulting in lower bond strengths. Based on the results of this study, this hypothesis or in vitro results could not be verified.

An analysis with mean observation period of up to 40.3 months could be considered medium term followup. DRCs are being followed up for longer period of time in order to observe whether adhesive interface between the composite and stained dentin would suffer from debonding due to fatigue.

In case of large extensive restorations as it were the situation in many of the cases, it was difficult to place rubberdam and especially the rubberdam clamp. Thus, placing rubberdam would rather complicate the treatment flow. Proximal box elevation could be an option for indirect restorations but for DRCs this approach would not bring any additional advantage. Based on the results of this study, it can be stated that the use of rubberdam is not detrimental on the survival of DRCs.

For the evaluation of the DRCs, the whole set of Ryge or FDI criteria were not implemented. Some of the criteria were also not found necessarily relevant for replacement of posterior restorations especially in a private practice setting. Therefore, we selected those criteria from the Ryge-list that were critical for real failure of posterior restorations. Criteria such as color stability, surface texture, staining does not indicate absolute failure. We preferred to score our restorations as failed if any operative intervention is needed in clinical situations of regular dental care delivery. Certainly, in an academic setting, other parameters could be considered in evaluation of quality of DRCs especially for comparison of different materials with one another.

The percentage of stained dentin surface in relation to the overall cavity surface and the presence of enamel were not calculated in this study. As shear and compressive forces occurs during chewing and possibly more heavily in bruxing patients, main forces are expected to concentrate at the outline first, which 
is sustained by the reliable adhesion of resin materials to etched enamel. The presence of enamel might indeed contribute to retention in shear forces in the cervical regions of the restorations, ${ }^{28,29}$ but in extensive cavity designs like those in this study, the retention of the restorations may benefit from sufficient dentinal adhesion. ${ }^{30}$ In addition, during clinical function intermittent compressive forces are at least as challenging as shear stresses. ${ }^{31}$ Thus, long-term follow up of these restorations will verify whether failures would be experienced at the tooth-DRC interface of within the material itself as a consequence of fatigue forces.

\section{Conclusions}

Since no debonding was experienced during the course of this study with the materials used, it can be stated that in case of amalgam replacement by direct resin composites, dentin that is exposed upon amalgam removal, does not impair survival of extended cusp replacing restorations.

\section{Conflict of interest}

The authors did not have any commercial interest in any of the materials used in this study. 


\section{REFERENCES}

1. Van Nieuwenhuysen JP, D'Hoore W, Carvalho J, Qvist V. Long-term evaluation of extensive restorations in permanent teeth. Journal of Dentistry 2003;31:395-405.

2. Roulet JF. The problems associated with substituting composite resins for amalgam: a status report on posterior composites. Journal of Dentistry 1988;16:101-13.

3. Liebenberg WH. Assuring restorative integrity in extensive posterior resin composite restorations: pushing the envelope. Quintessence International 2000;31:153-64.

4. Deliperi S, Bardwell DN. Multiple cuspal-coverage direct composite restorations: functional and esthetic guidelines. Journal of Esthetic and Restorative Dentistry 2008;20:300-8.

5. Demarco FF, Corrêa MB, Cenci MS, Moraes RR, Opdam NJ. Longevity of posterior composite restorations: not only a matter of materials. Dental Materials 2012;28:87-101.

6. Scholtanus JD, Özcan M, Huysmans MC. Penetration of amalgam constituents into dentine. Journal of Dentistry 2009;37:366-73.

7. Harnirattisai C, Senawongse P, Tagami J. Microtensile bond strengths of two adhesive resins to discolored dentin after amalgam removal. Journal of Dental Research 2007;86:232-6.

8. Carvalho RM, Manso AP, Geraldeli S, Tay FR, Pashley DH. Durability of bonds and clinical success of adhesive restorations. Dental Materials 2012;28:72-86.

9. Kurosaki N, Fusayama T. Penetration of elements from amalgam into dentin. Journal of Dental Research 1973;52:309-17.

10. Van der Linden LWJ, Van Aken J. The origin of localized increased radiopacity in the dentin. Oral Surgery 1973;35:862-71.

11. Rudolphy MP, Van Amerongen JP, Ten Cate JM. Radiopacities in dentin under amalgam restorations. Caries Research 1994;28:240-5. 
12. Nakajima M, Sano H, Burrow MF, Tagami J, Yoshiyama M, Ebisu S, Ciucchi B, Russell CM, Pashley DH. Tensile bond strength and SEM evaluation of caries-affected dentin using dentin adhesives. Journal of Dental Research 1995;74:1679-88.

13. Nakajima M, Sano H, Urabe I, Tagami J, Pashley DH. Bond strengths of single-bottle dentin adhesives to caries-affected dentin. Operative Dentistry 2000;25:2-10.

14. Yoshiyama M, Tay FR, Doi J, Nishitani Y, Yamada T, Itou K, Carvalho RM, Nakajima M, Pashley DH. Bonding of self-etch and total-etch adhesives to carious dentin. Journal of Dental Research 2002;81:556-60. 15. Pereira PN, Nunes MF, Miguez PA, Swift EJ Jr. Bond strengths of a 1-step self-etching system to cariesaffected and normal dentin. Operative Dentistry 2006;31:677-81.

16. Omar H, El-Badrawy W, El-Mowafy O, Atta O, Saleem B. Microtensile bond strength of resin composite bonded to caries-affected dentin with three adhesives. Operative Dentistry 2007;32:24-30.

17. Manhart J, Chen H, Hamm G, Hickel R. Buonocore Memorial Lecture. Review of the clinical survival of direct and indirect restorations in posterior teeth of the permanent dentition. Operative Dentistry 2004;29:481508.

18. Opdam NJ, Bronkhorst EM, Roeters JM, Loomans BA. A retrospective clinical study on longevity of posterior composite and amalgam restorations. Dental Materials 2007;23:2-8.

19. Opdam NJ, Bronkhorst EM, Loomans BA, Huysmans MC. 12-Year survival of composite vs. amalgam restorations. Journal of Dental Research 2010;89:1063-7.

20. Heintze SD, Rousson V. Clinical effectiveness of direct class II restorations - a meta-analysis. Journal of Adhesive Dentistry 2012;14:407-31.

21. Laegreid T, Gjerdet NR, Johansson AK. Extensive composite molar restorations: 3 years clinical evaluation. Acta Odontologica Scandinavia 2012;70:344-52. 
22. Deliperi S, Bardwell DN. Clinical evaluation of direct cuspal coverage with posterior composite resin restorations. Journal of Esthetic and Restorative Dentistry 2006;18:256-65.

23. Ferracane JL. Resin composite - state of the art. Dental Materials 2011;27:29-38.

24. Ferracane JL. In vitro evaluation of the marginal degradation of dental composites under simulated occlusal loading. Dental Materials 1999;15:262-7.

25. Wendt SL Jr, Leinfelder KF. Clinical evaluation of Clearfil photoposterior: 3-year results. American Journal of Dentistry 1992;5:121-5.

26. Van Meerbeek B, De Munck J, Yoshida Y, Inoue S, Vargas M, Vijay P, Van Landuyt K, Lambrechts P, Vanherle G. Buonocore memorial lecture. Adhesion to enamel and dentin: current status and future challenges. Operative Dentistry 2003;28:215-35.

27. Perdigão J. New developments in dental adhesion. Dental Clinics of North America 2007;51:333-7.

28. Rees JS, Jacobsen PH. The effect of cuspal flexure on a buccal Class $V$ restoration: a finite element study. Journal of Dentistry 1998;26:361-7.

29. Rees JS, Jacobsen $\mathrm{PH}$. The effect of interfacial failure around a class $\mathrm{V}$ composite restoration analysed by the finite element method. Journal of Oral Rehabilitation 2000;27:111-6.

30. Van Meerbeek B, Perdigão J, Lambrechts P, Vanherle G. The clinical performance of adhesives. Journal of Dentistry 1998;26:1-20.

31. da Rosa Rodolpho PA, Cenci MS, Donassollo TA, Loguércio AD, Demarco FF. A clinical evaluation of posterior composite restorations: 17-year findings. Journal of Dentistry 2006;34:427-35. 


\section{Captions to the legends and tables:}

Tables:

Table 1. The brand, type, manufacturer, and chemical composition of the main materials used in this study.

Table 2. Inclusion and exclusion criteria for teeth.

Table 3. Protocol for conditioning the cavity and application of resin composite.

Table 4. Specified criteria for failure of restorations.

Table 5. Distribution of restored teeth and restoration types in the maxilla and mandible. MODP: Mesioocclusal distopalatinal; MODB: Mesioocclusal distobuccal; MODL: Mesioocclusal distolingual.

\section{Figures}

Figs. 1a-b Representative photos of a) dentin substrate with stained with amalgam ions after amalgam removal, b) restoration with direct resin composite.

Fig. 2 Event-free survival rates of direct resin composite restorations on stained dentin substrate with amalgam ions in extensive cavities $(\mathrm{N}=118)$. 


\section{Tables:}

\begin{tabular}{|c|c|c|c|}
\hline Brand & Type & Manufacturer & Chemical composition \\
\hline Ultra-Etch & Etching gel & $\begin{array}{l}\text { Ultradent, South Jordan, } \\
\text { USA }\end{array}$ & $35 \%$ phosphoric acid \\
\hline $\begin{array}{l}\text { Quadrant } \\
\text { Unibond Primer }\end{array}$ & Dentin primer & $\begin{array}{l}\text { Cavex Holland, Haarlem, } \\
\text { The Netherlands }\end{array}$ & $\begin{array}{l}\text { Methacrylate-based monomers } 39.6 \mathrm{w} \% \text {, } \\
\text { carboxylic acid based monomer } 6.3 \mathrm{w} \% \text {, } \\
\text { polymerization catalysts } 0.3 \mathrm{w} \% \\
\text { solvents } 53.8 \mathrm{w} \%\end{array}$ \\
\hline $\begin{array}{l}\text { Quadrant } \\
\text { Unibond Sealer }\end{array}$ & $\begin{array}{l}\text { Adhesive } \\
\text { resin }\end{array}$ & Cavex Holland & $\begin{array}{l}\text { Methacrylate-based momomers } 69.4 \mathrm{w} \% \text {, } \\
\text { carboxylic acid based monomer } 4.3 \mathrm{w} \% \text {, } \\
\text { polymerization catalysts } 0.5 \mathrm{w} \% \text {, } \\
\text { silica and silicate glass fillers } 25.8 \mathrm{w} \%\end{array}$ \\
\hline $\begin{array}{l}\text { Clearfil } \\
\text { PhotoPosterior }\end{array}$ & $\begin{array}{l}\text { Resin } \\
\text { composite }\end{array}$ & $\begin{array}{l}\text { Kuraray Dental, Tokyo, } \\
\text { Japan }\end{array}$ & $\begin{array}{l}\text { Filler amount: } 86 \mathrm{w} \%, 71 \mathrm{vol} \% \\
\text { Filler type: silica and quartz } \\
\text { Mean filler particle size: } 4 \mu \mathrm{m} \\
\text { Monomer: bis-GMA }\end{array}$ \\
\hline
\end{tabular}

Table 1. The brand, type, manufacturer, and chemical composition of the main materials used in this study.

Inclusion criteria:
- Need of 3 surface restorations with coverage of at least 2 adjacent cusps in molars
- Need of 3 surface restorations with coverage of at least 1 cusp in premolars
- Presence of existing amalgam restorations on at least occlusal surface
- Presence of extensive black stained dentin upon removal of existing amalgam
- Lack of macromechanical retention necessary for non-adhesive restorations
- Absence of pain and endodontic complications
- Functional occlusal contacts with antagonist tooth
- At least 1 proximal contact
Exclusion criteria:
- Presence of cement base material underneath amalgam
- Incomplete vertical fractures in dentin

Table 2. Inclusion and exclusion criteria for teeth. 


\section{Protocol for conditioning and application of resin composite:}

1. Application of etching gel (20 s)

2. Rinsing with water spray (5s)

3. Changing cotton rolls and control of dry field

4. Gentle drying with compressed air

5. Application of primer (20 s)

6. Evaporation of solvent $(2 \mathrm{~s})$ by compressed air

7. Application of adhesive resin

8. Gently blowing excess adhesive resin

9. Photo-polymerization (20 s)

10. Application of composite in layers of max. $2 \mathrm{~mm}$

11. Photo-polymerization (20 s)

12. Repeating step 10 and 11 until slight overfill

13. Finishing and polishing

Table 3. Protocol for conditioning the cavity and application of resin composite.

\section{Criteria for failure of restorations:}

- caries was evident contiguously with the margin of the restoration, operative treatment indicated

- restoration was under-contoured, with dentin or base exposed

- contact was faulty (not self-correcting)

- occlusal height was reduced (occlusion affected)

- restoration was fractured

- restoration was missing or mobile partially or totally

- tooth structure was fractured

- restoration caused pain in tooth or adjacent tissue

- surface was rough and could not be refinished

- surface was deeply pitted, irregular grooves

- obvious crevice at margin was visible, dentin or base exposed

- endodontic treatment was indicated because of endodontic complications

- tooth needed to be extracted

Table 4. Specified criteria for failure of restorations. 


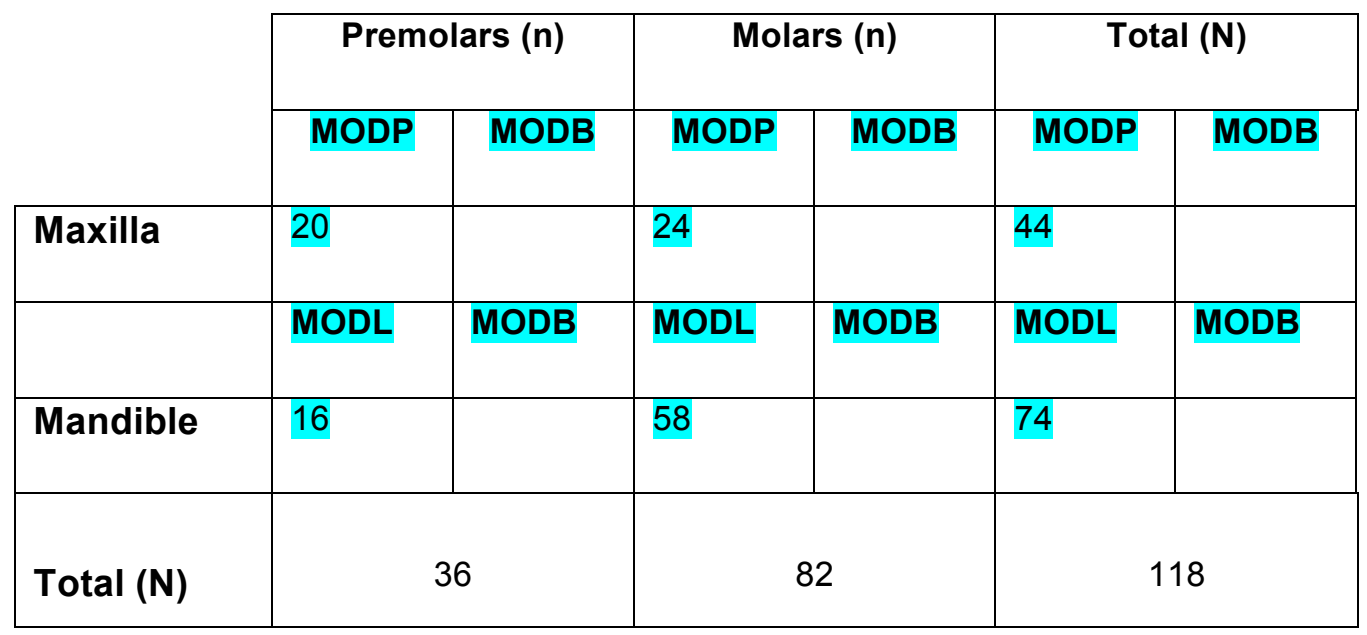

Table 5. Distribution of restored teeth and restoration types in the maxilla and mandible. MODP: Mesioocclusal distopalatinal; MODB: Mesioocclusal distobuccal; MODL: Mesioocclusal distolingual. 
Figures:

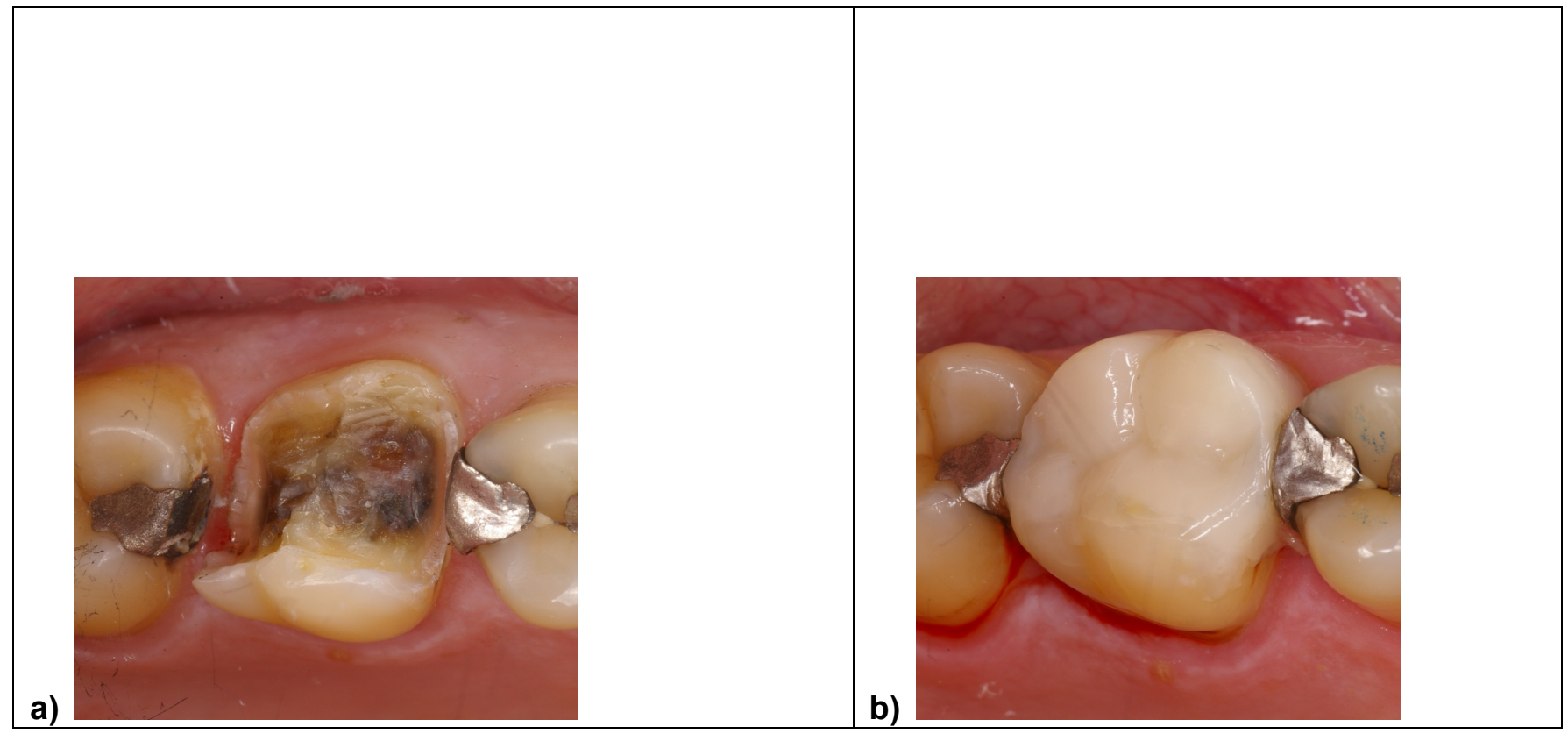

Figs. 1a-b Representative photos of a) dentin substrate with stained with amalgam ions after amalgam removal, b) restoration with direct resin composite.

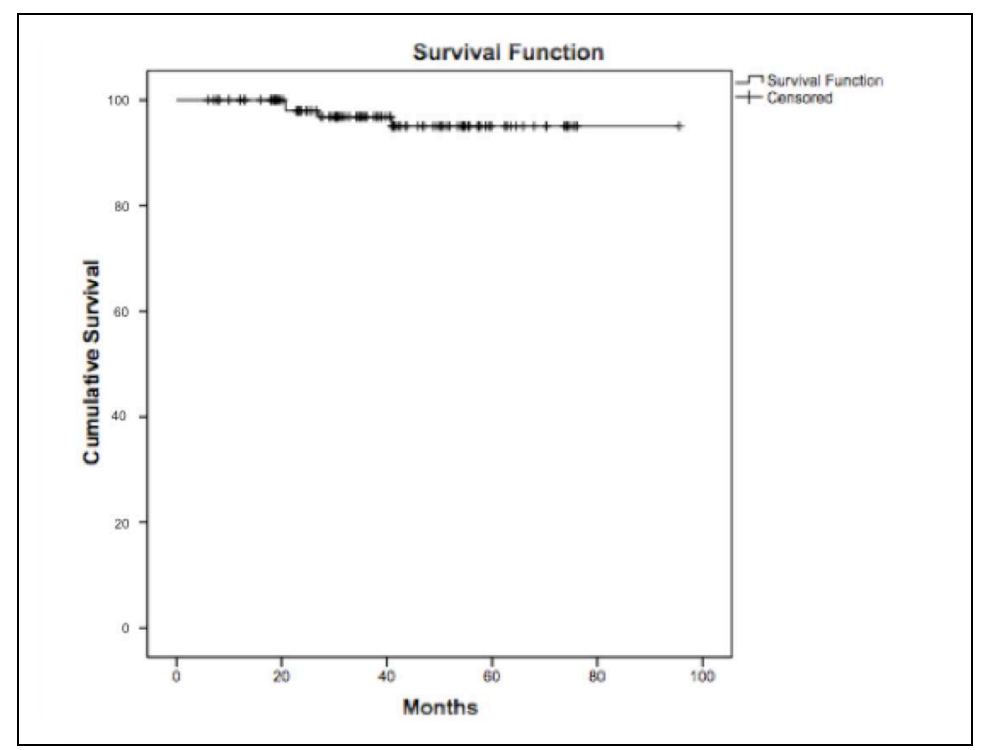

Fig. 2 Event-free survival rates of direct resin composite restorations on stained dentin substrate with amalgam ions in extensive cavities $(\mathrm{N}=118)$. 
